\section{ESTUDO NUMÉRICO DO CAMPO DE TENSÃO E DESLOCAMENTO DE PAINÉIS SANDUÍCHE HONEYCOMB COM EMPACOTAMENTO CÚBICO E ORTOTRÓPICO}

\author{
Thaís da Costa Dias ${ }^{(1)}$ (thaisdias.engmec@ hotmail.com), Larissa de Souza Pinto ${ }^{(2)}$ (larissap@ita.br), \\ Jorge Nei Brito $^{(3)}$ (brito@ufsj.edu.br). \\ (1) Universidade Federal de São João del-Rei (UFSJ) - PPMEC - Praça Frei Orlando, 170 - Centro, São João del-Rei - MG.
(2) Instituto Tecnológico de Aeronáutica (ITA) - Departamento de Eletrônica - Av. do Aeroporto s\no
${ }^{(3)}$ Universidade Federal de São João del-Rei (UFSJ) - DEMEC - Praça Frei Orlando, 170 - Centro, São João del-Rei - MG.
}

RESUMO: $O$ uso de compósitos estruturais está aumentando nos diferentes setores industriais devido às diversas vantagens destes materiais. Os compósitos estruturais se dividem em painéis sanduíche e laminados. Painéis sanduíche apresentam elevado módulo e resistência específicos, são constituídos por duas faces e um núcleo. Além das faces e núcleo poderem ser constituídos de diferentes tipos de materiais, o núcleo pode ter diferenciadas configurações geométricas. O presente trabalho analisou, através do método dos elementos finitos, as tensões e o deslocamento de painéis sanduíche com núcleo honeycomb circular, variando o empacotamento em cúbico e ortotrópico submetidos à flexão, o mesmo estudo foi realizado para placas de alumínio maciças com massas equivalentes aos respectivos painéis. As faces e núcleo dos painéis são de liga de alumínio. Foi calculada a rigidez à flexão analiticamente para os painéis. Para as configurações avaliadas todos os painéis sanduiche apresentaram um desempenho mecânico superior às suas respectivas placas de massa equivalente. O painel com empacotamento cúbico apresentou menores valores de tensão e deslocamento em relação ao ortotrópico, o que era esperado devido ao fato do cúbico apresentar maior momento de inércia e também maior rigidez a flexão.

PALAVRAS-CHAVE: compósitos estruturais, painéis sanduíche, método dos elementos finitos, empacotamento cúbico, empacotamento ortotrópico.

\section{INTRODUÇÃO}

As novas exigências da atualidade tornam necessária a busca de novos materiais com bom desempenho mecânico e baixo peso. Um exemplo desses novos materiais são os painéis sanduíche que são uma das divisões do compósito estrutural. Segundo Daniel e Ishai (2006), o compósito estrutural é projetado para obter um desempenho superior ao dos materiais convencionais, como metálicos, poliméricos e cerâmicos.

Inicialmente aplicados nas indústrias aeroespacial e naval, foi a partir dos anos 1960 que os painéis sanduíche começaram a conhecer novos campos de aplicação, nomeadamente da construção. Os materiais compósitos, surgidos na década de 1940, foram alargando o seu campo de aplicação, começando a ser utilizados na indústria em maior escala, a partir dos anos 1980 (ALLEN, 1969).

Os painéis sanduíche geralmente são constituídos por duas faces finas e um núcleo entre elas. As faces podem ser de metal ou compósito e o núcleo geralmente é de honeycomb ou espuma. Essa combinação resulta em vantagens como o aumento da resistência e rigidez, bem como da absorção de energia e resistência específica. Portanto, dependendo do tipo de aplicação pode ser relevante utilizar um painel sanduíche no lugar de um material convencional maciço. O núcleo com 
espessura elevada tem como objetivo o aumento do momento de inércia do material, aumentando a sua resistência à flexão. A utilização de um núcleo espesso e leve permite que seja obtido um material muito mais rígido que um material de peso igual constituído unicamente pelo material da face (ALLEN, 1969).

Além da combinação de diferentes materiais no núcleo e na face, os painéis sanduíche permitem diversas configurações geométricas no núcleo. Diante de tudo isso o painel pode ser projetado de forma a otimizar seu desempenho mecânico. Casos simples podem ser resolvidos analiticamente usando várias teorias que já foram desenvolvidas, mas estruturas complexas requerem o método dos elementos finitos.

Neste contexto, o presente trabalho propõe o estudo do campo de tensão e deslocamento à flexão de painéis sanduíche com faces e núcleo de liga de alumínio, o núcleo é constituído de honeycomb circular, um painel possui empacotamento cúbico e o outro ortotrópico. $\mathrm{O}$ mesmo estudo foi aplicado a duas placas de liga de alumínio com massa equivalente a de cada painel avaliado. Também foi calculada a rigidez à flexão dos painéis analiticamente. Posteriormente, todos os resultados foram comparados.

\section{OBJETIVOS}

- Calcular analiticamente a rigidez à flexão de painéis sanduíche de núcleo e faces de liga de alumínio com empacotamento cúbico e ortotrópico;

- Simular os painéis e placas sob ensaio de flexão, para a obtenção da tensão e o deslocamento;

- Comparar todos os resultados obtidos.

\section{REFRENCIAL TEÓRICO}

\subsection{Painéis Sanduíche}

O painel sanduíche (Figura 1) é constituído por duas faces finas, rígidas e resistentes, unidas a um núcleo espesso de baixa densidade por meio de um adesivo usualmente polimérico. O núcleo pode ser preenchido com espumas poliméricas, ou apresentar células de parede fina do tipo honeycomb, com formato hexagonal, circular ou aleatório.

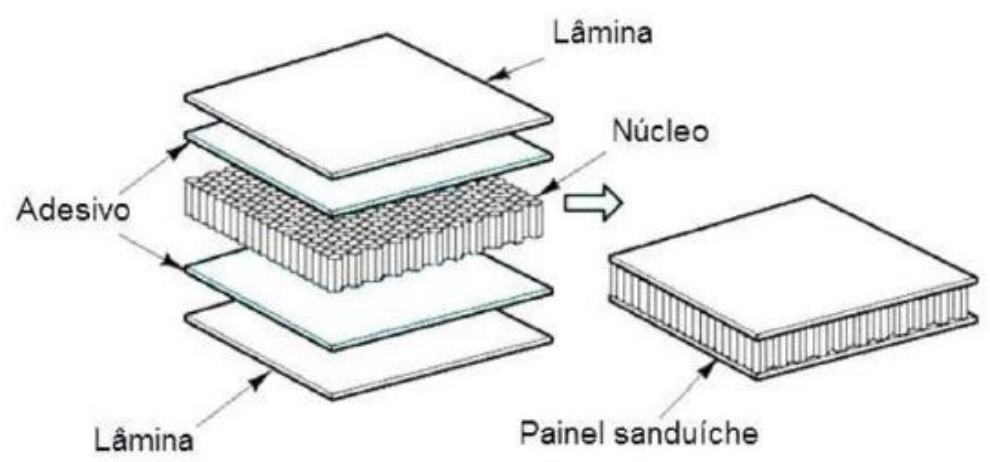

Figura 1. Estrutura típica de compósito sanduíche com núcleo honeycomb (Fonte: Almeida, 2009). 
Com relação à estrutura, é possível distinguir os núcleos dos materiais sanduíche em duas categorias: núcleos homogêneos e núcleos não-homogêneos. Os núcleos não-homogêneos dividemse ainda em três categorias, de acordo com o suporte oferecido às lâminas: núcleo pontual, canelados e em honeycomb (ALMEIDA, 2009).

Os núcleos do tipo honeycomb podem ser constituídos de células hexagonais, circulares ou aleatórias. Diversas pesquisas têm sido realizadas para investigar e comparar as propriedades do núcleo com geometria circular e hexagonal. Os resultados revelam que honeycombs circulares apresentam resistência e módulo à flexão específicos superiores às hexagonais devido às restrições na estrutura, sendo, portanto, mais promissores para serem utilizados como materiais estruturais (ORUGANTI e GHOSH, 2008; LIN et al., 2012).

Outro fator que afeta as propriedades dos painéis sanduíche é a geometria de empacotamento do núcleo honeycomb, definida de acordo com o ângulo e o espaçamento entre as células adjacentes, podendo ser do tipo hexagonal, cúbica ou ortotrópica, como apresentados na Figura 2 para as células circulares.
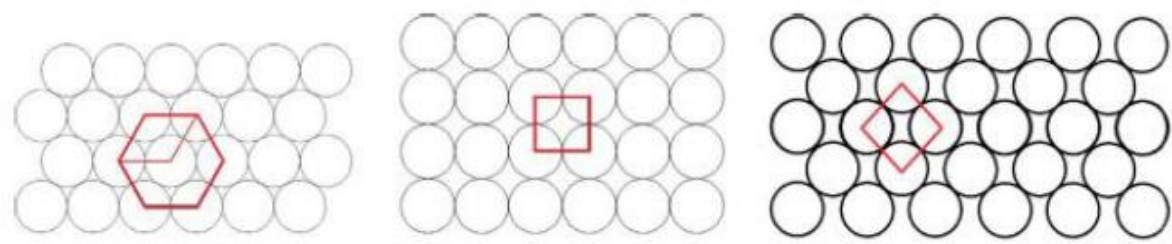

Figura 2. Empacotamento do núcleo: (a) hexagonal, (b) cúbico, (c) ortotrópico. (Fonte: Adaptado de Hu et al., 2015; Gotkhindi e Shima, 2015).

\subsection{Método dos Elementos Finitos}

De acordo com Norton (2013) para analisar as tensões e a deflexão em uma peça pode-se dividir o seu volume em um conjunto finito de elementos contíguos e discretos e resolver um conjunto (grande) de equações, cada uma das quais aplicadas sobre um elemento e seus nós, que conectam os elementos entre si. As tensões variam através do contínuo de qualquer componente. Dividindo esse componente em um número finito de elementos discretos conectados pelos seus nós (chamados de malha), pode-se obter uma aproximação das tensões e deformações, em qualquer parte do componente, para um dado conjunto de condições de contorno e de cargas aplicadas em alguns nós da estrutura.

Para a análise estrutural estática tem-se $[\mathrm{k}]\{\mathrm{d}\}=\{\mathrm{f}\}$, onde $\mathrm{k}$ é a matriz de rigidez, $\mathrm{d}$ é o vetor de deslocamento nodal e f é o vetor de forças internas do elemento. Existem vários softwares que já possuem o método dos elementos finitos implementado, um exemplo é o ANSYS.

\section{MATERIAIS E MÉTODOS}

\subsection{Cálculo da Rigidez à Flexão Analiticamente}

A rigidez a flexão (D) é o produto do módulo de elasticidade (E) e o momento de área (I), D = E.I. Portanto, a rigidez a flexão para uma viga sanduíche é a soma da rigidez a flexão das faces e 
núcleo, medida considerando o centroide no eixo c'c'. Através da Equação 1 é possível calcular a rigidez a flexão do painéis e na Figura 3 tem-se o significado de cada incógnita da equação. $\mathrm{E}_{\mathrm{f}}$ é o módulo de elasticidade da face e $\mathrm{E}_{\mathrm{c}} \mathrm{o}$ módulo do núcleo.

$$
D=E_{f} \cdot \frac{b\left(h^{3}-c^{3}\right)}{12}+E_{c} \cdot \frac{b c^{3}}{12}
$$
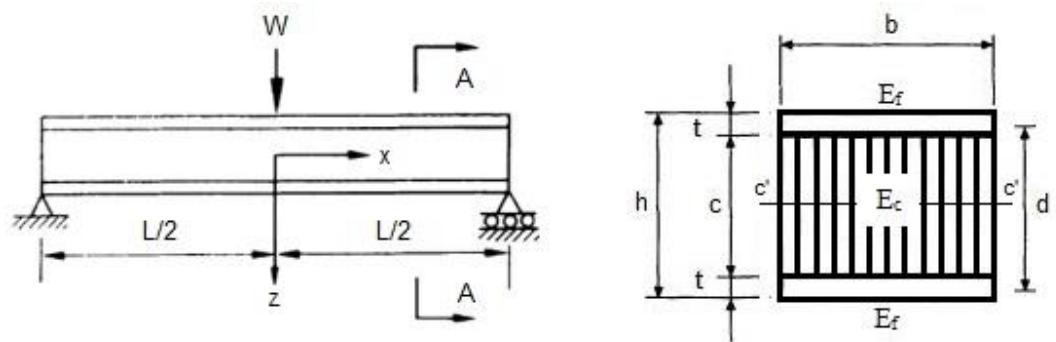

Figura 3. Dimensões do painel sanduíche (seção AA). (Fonte: Adaptado de Allen (1969) e Bitzer (1997).

A densidade volumétrica pode ser calculada dividindo a massa do painel sanduíche pelo seu respectivo volume.

\subsection{Estudo dos Campos de Tensão e Deformação Através do Método dos Elementos Finitos}

Os desenhos foram feitos no software SolidWorks 2014, painéis sanduíche com empacotamento cúbico e ortotrópico (Figura 4), e posteriormente importados para o ANSYS 14.5. Além disso, foram desenhadas duas placas com massa equivalente a cada painel, com largura e comprimento aproximados aos respectivos painéis.

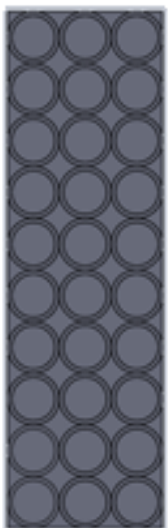

a)

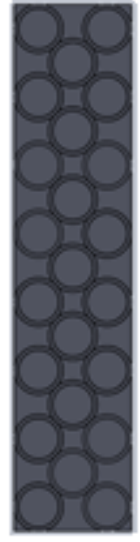

b)

Figura 4. Painel sanduíche: a) empacotamento cúbico e b) empacotamento ortotrópico.

Nas Figuras 5 e 6 têm-se as cotas dos painéis e das respectivas placas. Cada anel do núcleo possui o diâmetro de $20 \mathrm{~mm}$ e espessura de $1,6 \mathrm{~mm}$. A espessura de cada face é de $0,5 \mathrm{~mm}$ e a 
altura do núcleo é de $13 \mathrm{~mm}$ para todos os painéis. Ambas as faces e anéis são constituídas de liga de alumínio, bem como suas placas equivalentes. O span (abertura entre os apoios) para todos os desenhos é de $150 \mathrm{~mm}$.

a)

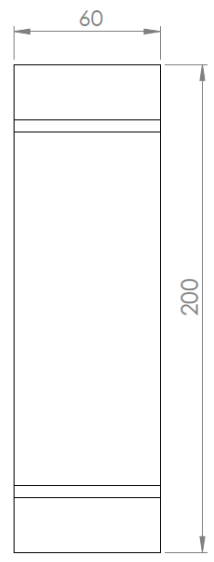

b)

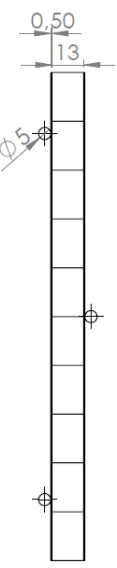

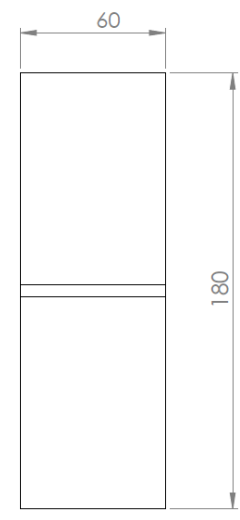

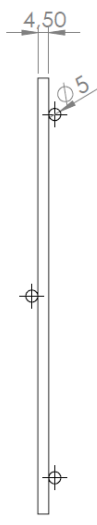

Figura 5. Cotas: a) painel sanduíche com empacotamento cúbico e b) placa (1) com massa equivalente ao painel com empacotamento cúbico

a)

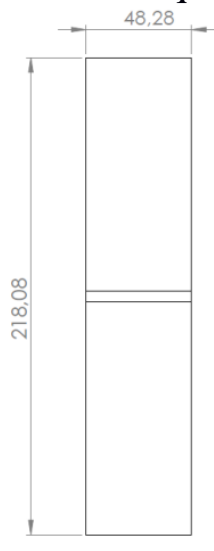

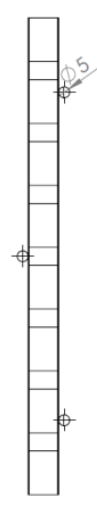

b)

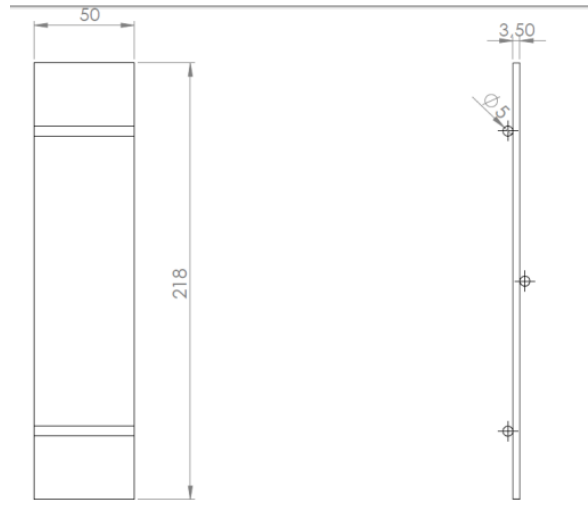

Figura 6. Cotas: a) painel sanduíche com empacotamento ortotrópico e b) placa (2) com massa equivalente ao painel com empacotamento ortotrópico

O estudo do campo de tensão e deslocamento dos dois painéis sanduíche e placas foram realizados pelo método dos elementos finitos através do software ANSYS versão 14.5. O desenho foi importado para o software e foram definidas as propriedades (módulo de elasticidade e coeficiente de Poisson) de acordo com a própria biblioteca de materiais do programa, apresentadas na Tabela 1 para o aço e alumínio e simulado um ensaio de flexão de três pontos. Foram considerados os apoios de aço e os painéis e placas totalmente de liga de alumínio. A densidade da liga de alumínio é de $2,7 \mathrm{~g} / \mathrm{cm}^{3}$. Na Figura 7 têm-se as condições de contorno, onde os apoios inferiores foram considerados fixos (B) e no superior (A) foi aplicado um carregamento de $200 \mathrm{~N}$, foi definido dessa forma para todas as simulações. 
Tabela 1. Propriedades dos materiais.

\begin{tabular}{cccc}
\hline & $\begin{array}{c}\text { Módulo de elasticidade } \\
(\mathrm{GPa})\end{array}$ & $\begin{array}{c}\text { Coeficiente de } \\
\text { Poisson }\end{array}$ & $\begin{array}{c}\text { Limite de escoamento } \\
(\mathrm{MPa})\end{array}$ \\
\hline Liga de & & & \\
alumínio & 71 & 0,33 & 280 \\
Aço & 200 & 0,3 & 250 \\
\hline
\end{tabular}

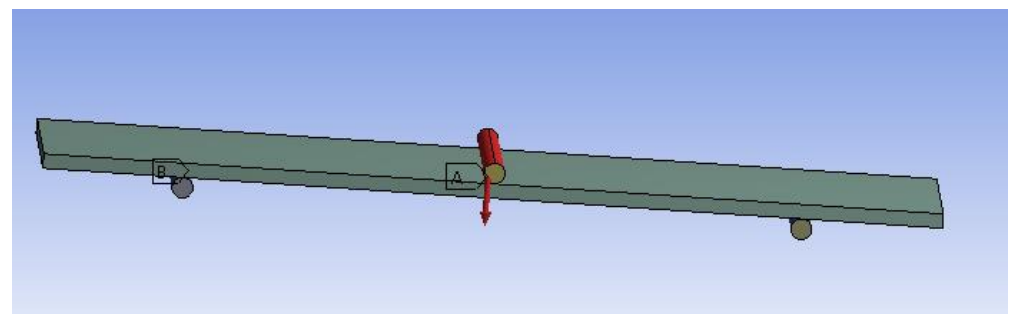

Figura 7. Condições de contorno

Gerou-se uma malha de quadriláteros para todas as simulações, conforme a Figura. O painel cúbico contém 33986 nós e 4443 elementos. A placa 1 (massa equivalente ao painel cúbico) contém 3332 nós e 536 elementos. O painel ortotrópico contém 30197 nós e 4230 elementos. A placa 2 (massa equivalente ao painel ortotrópico) contém 2694 nós e 430 elementos.

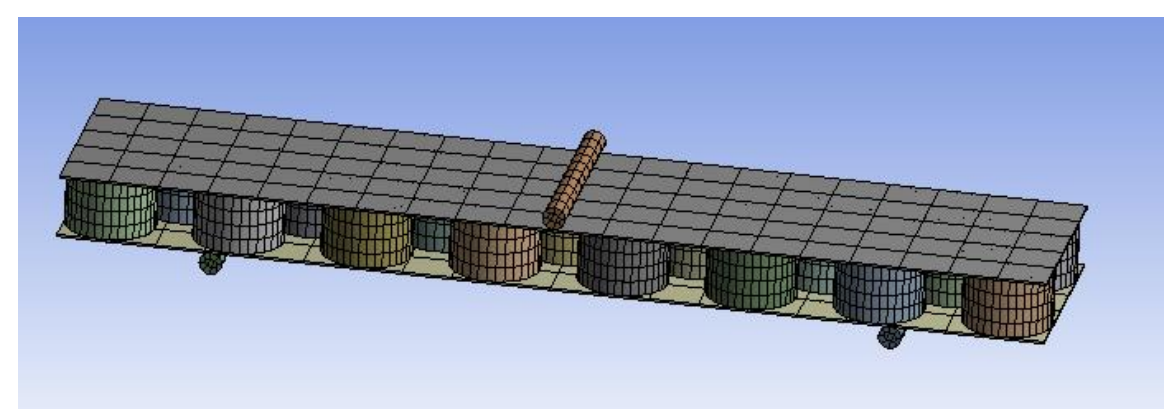

Figura 8. Malha

\section{RESULTADOS E CONCLUSÕES}

Calculou-se através do software SolidWorks 2014 a massa, volume das faces e anéis, a área de superfície e os momentos de inércia principais ( $\mathrm{Px}, \mathrm{Py}$ e $\mathrm{Pz}$ ) tomados no centro de massa, conforme a Tabela 2. 
Tabela 2. Massa, volume, área de superfície e momentos de inércia dos painéis e placas.

\begin{tabular}{lrlrrrr}
\hline & $\begin{array}{l}\text { Massa } \\
(\mathrm{g})\end{array}$ & $\begin{array}{l}\text { Volume } \\
\left(\mathrm{mm}^{3}\right)\end{array}$ & $\begin{array}{l}\text { Área de } \\
\text { superfície } \\
\left(\mathrm{mm}^{2}\right)\end{array}$ & Px $\left(\mathrm{g} \cdot \mathrm{mm}^{2}\right)$ & Py $\left(\mathrm{g} . \mathrm{mm}^{2}\right)$ & Pz $\left(\mathrm{g} \cdot \mathrm{mm}^{2}\right)$ \\
\hline Cúbico & 129,7904 & 48070,5102 & 99157,447 & 42691,9742 & 436389,4528 & 473384,4647 \\
Ortotrópico & 103,0971 & 38184,0979 & 81474,9402 & 21443,215 & 409376,5335 & 426124,688 \\
Placa 1 & 131,22 & 48600 & 23760 & 39587,4337 & 354515,4337 & 393660 \\
Placa 2 & 103,005 & 38150 & 23676 & 21564 & 408039,2859 & 429393,51 \\
\hline
\end{tabular}

A rigidez a flexão do painel sanduíche com empacotamento cúbico calculada pela Equação 1 é de 9,6.108 N.mm² e para o painel com empacotamento ortotrópico é de 7,73.108 N.mm². Portanto, para estas condições o painel com empacotamento cúbico apresenta maior rigidez. A densidade volumétrica do painel cúbico é de $0,773 \mathrm{~g} / \mathrm{cm}^{3}$ e do painel ortotrópico de $0,7 \mathrm{~g} / \mathrm{cm}^{3}$, sendo ambos os painéis muito leves e com uma diferença bem pequena entre si.

Os resultados para a simulação da tensão no painel com empacotamento cúbico e a tensão na placa de massa equivalente encontram-se respectivamente na Figura 9. No painel cúbico o carregamento é aplicado entre duas fileiras de anéis, a tensão máxima de 12,219 MPa ocorre na face, na porção ao centro dos anéis próximos ao carregamento. Na placa de alumínio com massa equivalente ao painel a tensão máxima de 12,666 MPa ocorre também ao centro, próximo ao carregamento, sendo um pouco maior que a tensão no painel, mas ambas abaixo do limite de escoamento do material. 

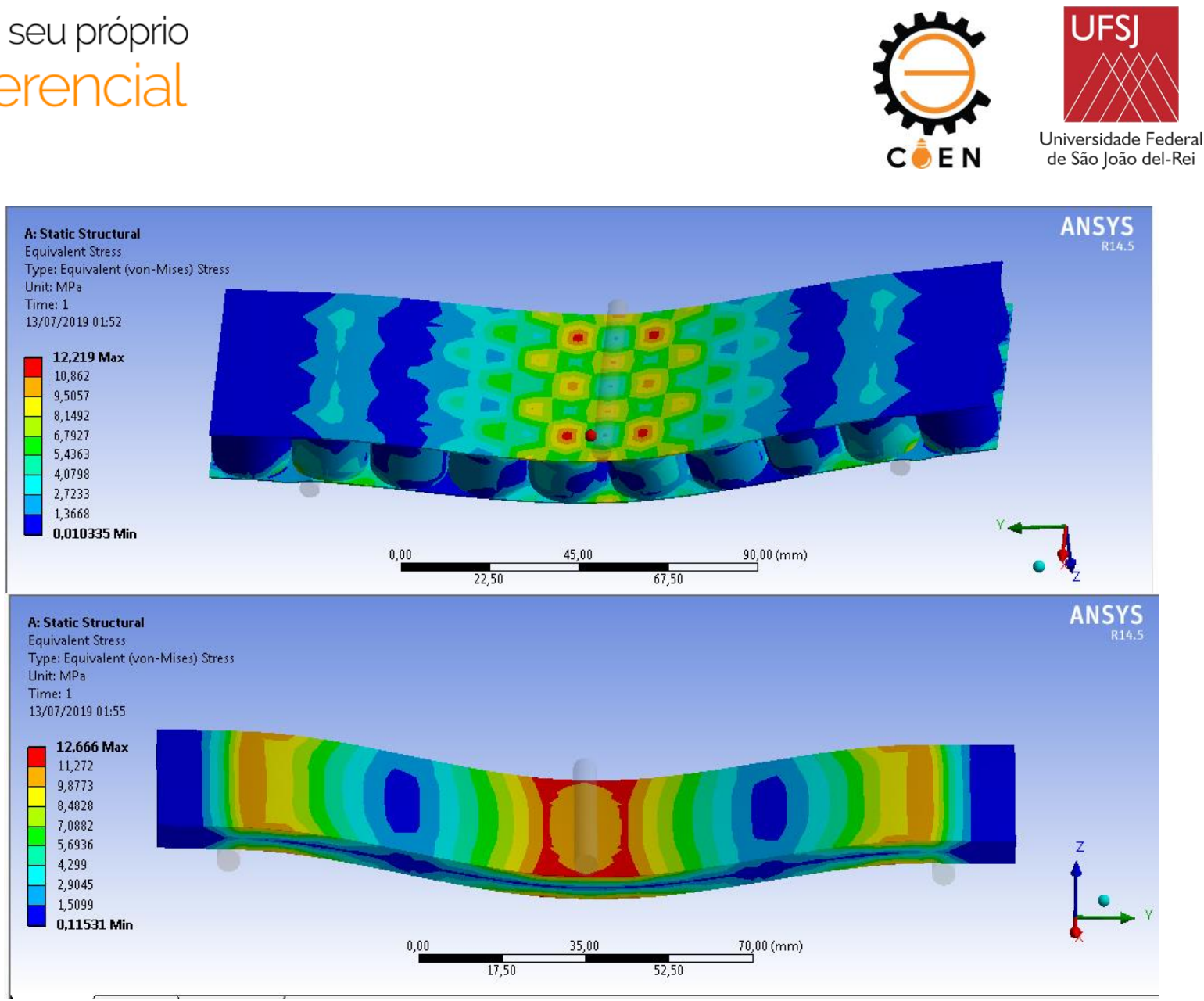

Figura 9. Tensão no painel com empacotamento cúbico e placa 1.

O deslocamento máximo na direção perpendicular à face do painel sanduíche de empacotamento cúbico (Figura 10) foi de $0,023 \mathrm{~mm}$ ao centro e para a placa de massa equivalente de $0,075 \mathrm{~mm}$. O painel teve um menor deslocamento se comparado à placa de massa equivalente. 

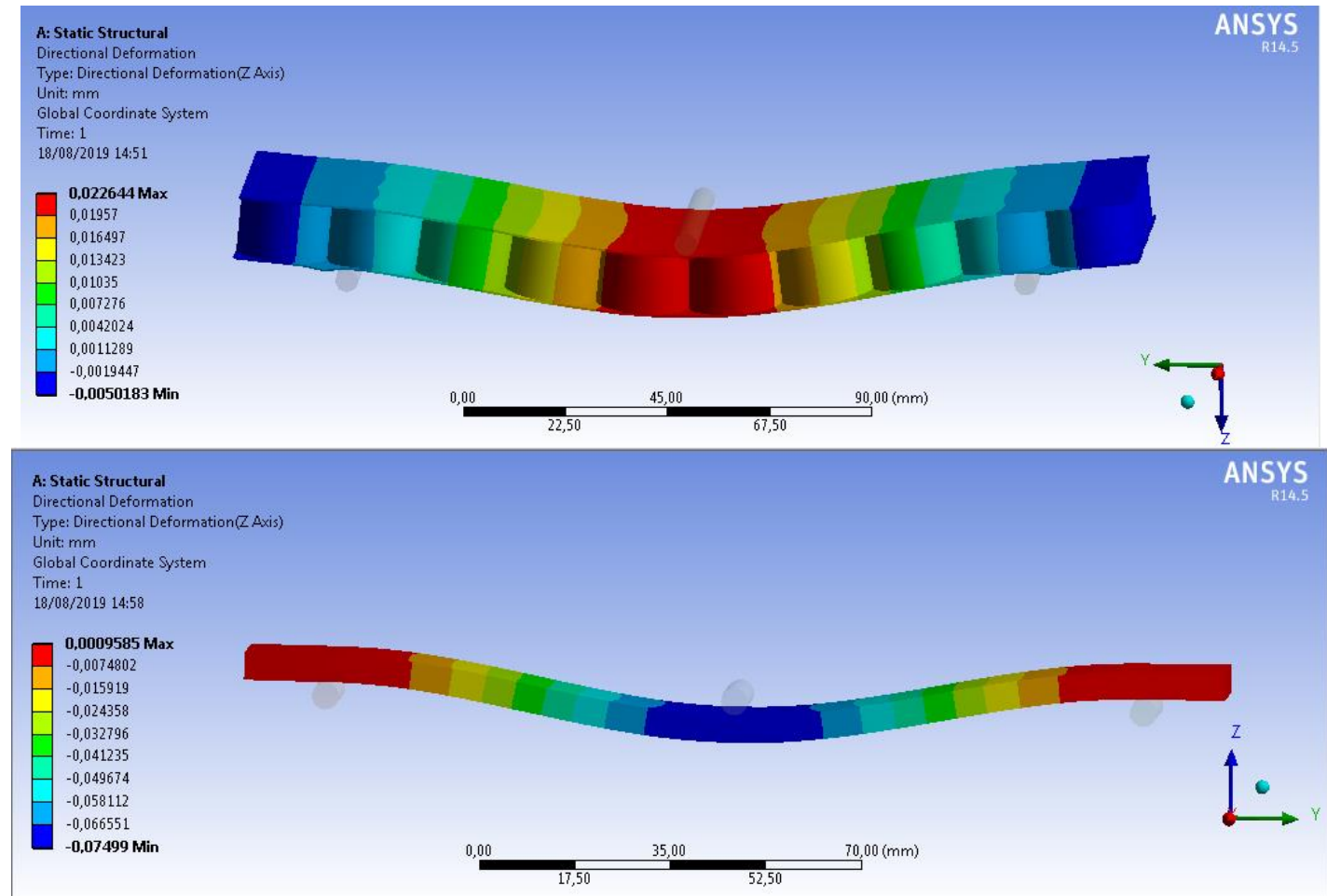

Figura 10. Deslocamento no painel com empacotamento cúbico e placa 1.

Os resultados para a simulação da tensão no painel com empacotamento ortotrópico e a tensão na placa de massa equivalente encontram-se respectivamente na Figura 11. No painel ortotrópico o carregamento é aplicado em uma fileira que contém apenas 1 anel, a tensão máxima de 18,012 MPa ocorre em uma pequena região dos anéis que estão próximos aos apoios fixos. Na placa de alumínio com massa equivalente ao painel a tensão máxima de 34,6447 MPa ocorre próximo aos apoios fixos, mas ambas abaixo do limite de escoamento do material. 

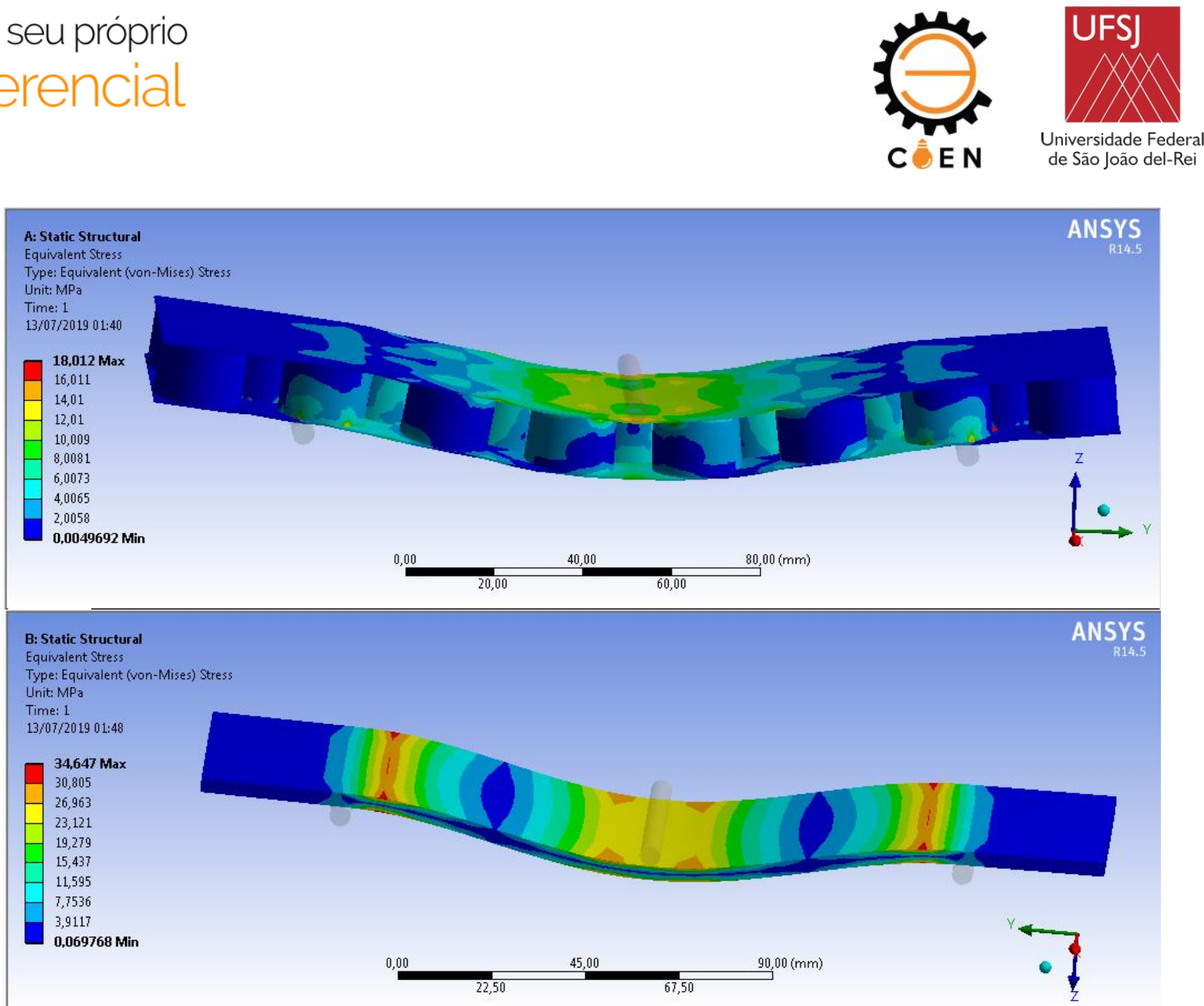

Figura 11. Tensão no painel com empacotamento ortotrópico e placa 2.

O deslocamento máximo na direção perpendicular à face do painel sanduíche de empacotamento ortotrópico (Figura 12) foi de $0,035 \mathrm{~mm}$ ao centro e para a placa de massa equivalente de $0,26 \mathrm{~mm}$. Novamente, o painel teve um menor deslocamento se comparado à placa de massa equivalente. 

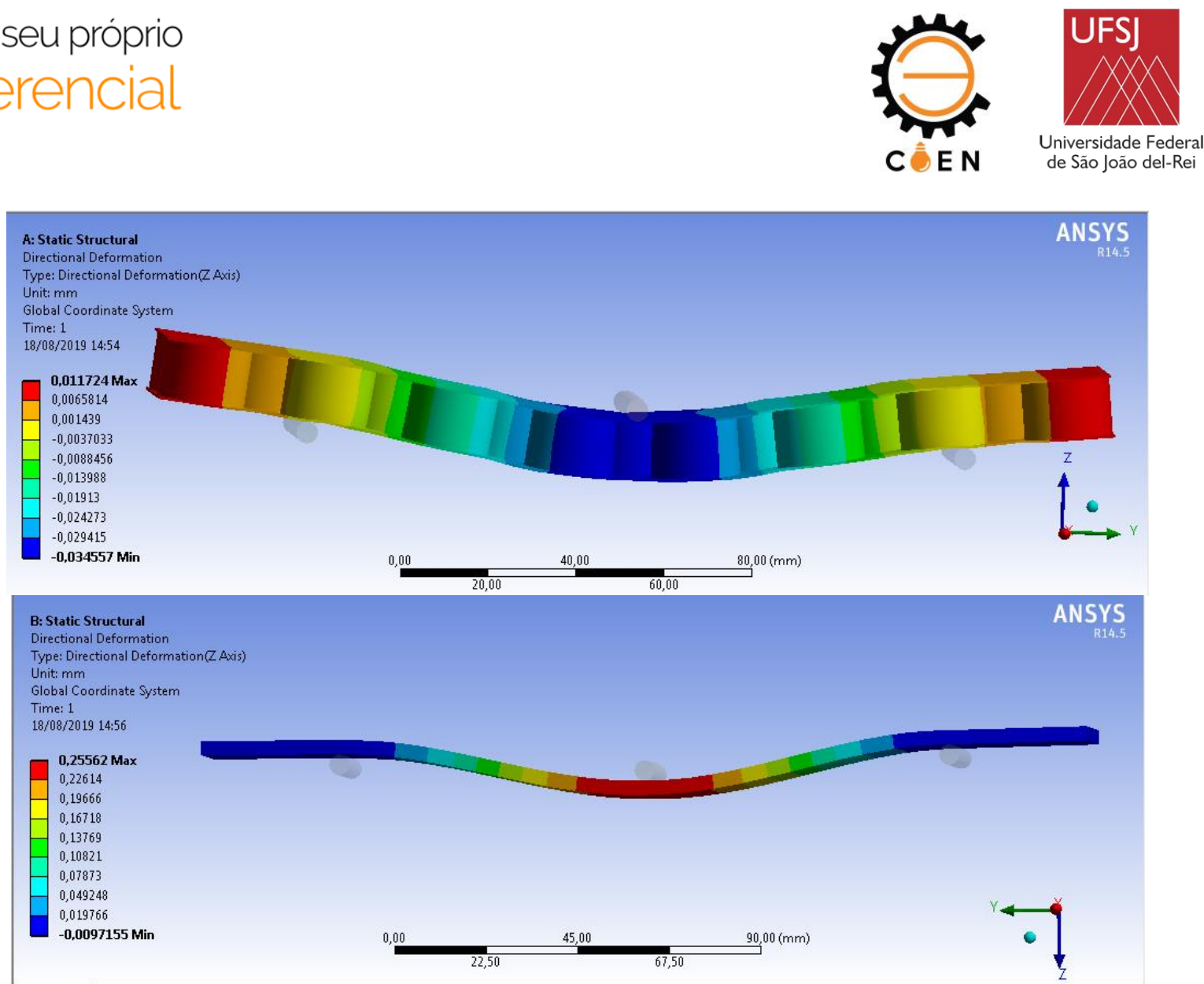

Figura 12. Deslocamento no painel com empacotamento ortotrópico e placa 2.

Portanto, em todos os casos os painéis obtiveram um desempenho superior ao de suas placas com respectivas massas equivalentes, apresentando menores valores de tensão e deslocamento. Para as condições analisadas o painel com empacotamento cúbico apresentou menores valores de tensão e deslocamento se comparado ao de empacotamento ortotrópico, o que era de se esperar já que o painel cúbico apresentou maiores valores de momento de inércia, bem como uma maior rigidez à flexão. Então, dependendo da aplicação pode ser mais conveniente utilizar um painel sanduíche do que o material da face na forma maciça, dessa forma é possível obter um melhor desempenho mecânico aliado a um baixo peso da estrutura. Além disso, as diferentes configurações do núcleo permitem melhorar as propriedades mecânicas e o método dos elementos finitos pode ser útil durante o projeto do painel.

\section{DIREITOS AUTORAIS.}

Os autores são os únicos responsáveis pelo conteúdo das informações contidas neste artigo.

\section{REFERÊNCIAS}

ALLEN, H. G. Analysis and design of structural sandwich panels. Pergamon Press, 1969. 
ALMEIDA, M. I. A. Comportamento estrutural de painéis sanduíche compósitos para aplicações na indústria da construção. Dissertação de Mestrado em Engenharia Civil - Universidade Técnica de Lisboa. 2009.

BITZER, T. Honeycomb Technology: Materials, Design, Manufacturing, Applications and Testing. Springer, 1997.

DANIEL, I. M.; ISHAI, O. Engineering mechanics of composite materials. New York: Oxford University Press, 2006.

GOTKHINDI, T. P.; SIMHA, K. R. Y. In-plane effective shear modulus of generalized circular honeycomb structures and bundled tubes in a diamond arrays structure. International Journal of Mechanical Sciences, v. 101-102, p. 292-308, 2015.

HU, L. L.; HE, X. L.; WU, G. P.; YU, T. X. Dynamic crushing of the circular-celled honeycombs under out-of-plane impact. International Journal of Impact Engineering, v. 75, p. 150$161,2015$.

LIN, T. -C.; CHEN, T.-J.; HUANG, J.-S. In-plane elastic constants and strengths of circular cell honeycombs. Composite Science and Technology, v. 72, p. 1380-1386, 2012.

NORTON, R. L. Projeto de Máquinas: uma abordagem integrada. Porto Alegre: Bookman, 2013.

ORUGANTI, R. K.; GHOSH, A. K. FEM analysis of transverse creep in honeycomb structures. Acta Materialia, v. 56, n. 4, p. 726-735, 2008. 


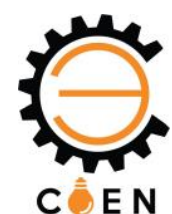

NUMERICAL STUDY OF THE STRESS FIELD AND DISPLACEMENT OF HONEYCOMB SANDWICH PANELS WITH CUBIC AND ORTOTROPIC PACKAGING

\author{
Thaís da Costa Dias ${ }^{(1)}$ (thaisdias.engmec@ @otmail.com), Larissa de Souza Pinto ${ }^{(2)}$ (larissap@ita.br), \\ Jorge Nei Brito $^{(3)}$ (brito@ufsj.edu.br). \\ (1) Universidade Federal de São João del-Rei (UFSJ) - PPMEC - Praça Frei Orlando, 170 - Centro, São João del-Rei - MG. \\ ${ }^{(2)}$ Instituto Tecnológico de Aeronáutica (ITA) - Departamento de Eletrônica - Av. do Aeroporto $s \backslash n^{\circ}$ \\ ${ }^{(3)}$ Universidade Federal de São João del-Rei (UFSJ) - DEMEC - Praça Frei Orlando, 170 - Centro, São João del-Rei - MG.
}

ABSTRACT: The use of structural composites is increasing in different industrial sectors due to the various advantages of these materials. The structural composites are divided into sandwich and laminate panels. Sandwich panels have high specific modulus and strength, are made up of two faces and a core. In addition to the faces and core can be made of different types of materials, the core can have different geometric configurations. The present work analyzed, through the finite element method, the stress and displacement of circular honeycomb core sandwich panels, varying the cubic and orthotropic packing submitted to flexion. The same study was performed for massive aluminum plates with masses equivalent to respective panels. The faces and core of the panels are aluminum alloy. The flexural stiffness was calculated analytically for the panels. For the evaluated configurations all sandwich panels presented a mechanical performance superior to their respective plates of equivalent mass. The panel with cubic packing presented lower values of stress and displacement in relation to the orthotropic one, which was expected due to the fact that the cubic presented greater moment of inertia and also greater flexural stiffness.

KEYWORDS: structural composites, sandwich panels, finite element method, cubic packaging, orthotropic packaging. 